\title{
ON AN INTEGRAL INEQUALITY OF Z. OPIAL
}

BY

\author{
PAUL R. BEESACK
}

In a recent paper [3], $Z$. Opial proved the following interesting integral inequality:

Let $y(x)$ be of class $C^{1}$ on $0 \leqq x \leqq h$, and satisfy $y(0)=y(h)=0, y(x)>0$ on $(0, h)$. Then

$$
\int_{0}^{h}\left|y(x) y^{\prime}(x)\right| d x \leqq \frac{h}{4} \int_{0}^{h} y^{\prime 2}(x) d x
$$

The constant $h / 4$ is best possible.

In a note published at the same time, C. Olech [2] showed that (1) is valid for any function $y(x)$ which is absolutely continuous on $[0, h]$, and satisfies the boundary conditions $y(0)=y(h)=0$. Moreover, Olech's proof of (1) was much simpler than that of Opial. In this note we will give an even simpler proof of (1), and then show how this method of proof can be made to yield more general inequalities of the same type.

Under Olech's hypotheses on $y(x)$, if $0<\epsilon<X<h$ we have

$0 \leqq \int_{\epsilon}^{x}\left\{\left|y^{\prime}\right|-\frac{1}{x}|y|\right\}^{2} d x=\int_{e}^{x} y^{\prime 2} d x+\int_{\epsilon}^{x} \frac{y^{2}}{x^{2}} d x-2 \int_{e}^{x} \frac{1}{x}\left|y y^{\prime}\right| d x$,

whence

$$
2 \int_{\epsilon}^{x} \frac{1}{x}\left|y y^{\prime}\right| d x \leqq \int_{\epsilon}^{x} y^{\prime 2} d x+\int_{\epsilon}^{x} \frac{y^{2}}{x^{2}} d x
$$

where equality holds if and only if $y \equiv A x$. Now

$$
\begin{array}{r}
2 \int_{\epsilon}^{x} \frac{1}{x}\left|y y^{\prime}\right| d x=\left.\frac{2}{x} \int_{0}^{x}\left|y y^{\prime}\right| d t\right|_{\epsilon} ^{x}+2 \int_{\epsilon}^{x} \frac{1}{x^{2}}\left\{\int_{0}^{x}\left|y y^{\prime}\right| d t\right\} d x \\
=\frac{2}{X} \int_{0}^{x}\left|y y^{\prime}\right| d t-\frac{2}{\epsilon} \int_{0}^{\epsilon}\left|y y^{\prime}\right| d t+2 \int_{\epsilon}^{x} \frac{1}{x^{2}}\left\{\int_{0}^{x}\left|y y^{\prime}\right| d t\right\} d x
\end{array}
$$

so that

$$
\begin{aligned}
\frac{2}{X} \int_{0}^{x}\left|y y^{\prime}\right| d x \leqq & \int_{\epsilon}^{x} y^{\prime 2} d x+\int_{\epsilon}^{x} \frac{1}{x^{2}}\left\{y^{2}(x)-2 \int_{0}^{x}\left|y y^{\prime}\right| d t\right\} d x \\
& +\frac{2}{\epsilon} \int_{0}^{\epsilon}\left|y y^{\prime}\right| d x
\end{aligned}
$$

Received by the editors August 28, 1961. 
Since $0 \leqq y^{2}(x)=2 \int_{0}^{x} y y^{\prime} d t \leqq 2 \int_{0}^{x}\left|y y^{\prime}\right| d t$, we thus obtain

$$
\frac{2}{X} \int_{0}^{x}\left|y y^{\prime}\right| d x \leqq \int_{\epsilon}^{x} y^{\prime 2} d x+\frac{2}{\epsilon} \int_{0}^{\epsilon}\left|y y^{\prime}\right| d x,
$$

where equality holds only if $y \equiv A x$. Since $y^{\prime} \in L_{2}(0, X)$ it follows that $y(x)$ $=o\left(x^{1 / 2}\right)$ as $x \rightarrow 0+$. Again, using the Cauchy-Schwarz inequality, we have

$$
\int_{0}^{e}\left|y y^{\prime}\right| d x \leqq k \int_{0}^{\epsilon} x^{1 / 2}\left|y^{\prime}\right| d x \leqq \frac{k}{2^{1 / 2}} \epsilon\left(\int_{0}^{\epsilon}\left|y^{\prime}\right|^{2} d x\right)^{1 / 2} .
$$

Letting $\epsilon \rightarrow 0$ in (2) we obtain

$$
\int_{0}^{x}\left|y y^{\prime}\right| d x \leqq \frac{X}{2} \int_{0}^{x} y^{\prime 2} d x
$$

with equality only if $y \equiv A x$. The inequality (3) is valid for any function $y(x)$ absolutely continuous on $[0, X]$ satisfying the single boundary condition $y(0)=0$.

To obtain (1), we apply the same technique on the interval $[X, h]$ and find

$$
\int_{X}^{h}\left|y y^{\prime}\right| d x \leqq \frac{h-X}{2} \int_{X}^{h} y^{\prime 2} d x
$$

if $y(x)$ is absolutely continuous on $[X, h]$ with $y(h)=0$. Equality holds in (4) only if $y \equiv B(h-x)$. Combining (3) and (4) we obtain

$$
\int_{0}^{h}\left|y y^{\prime}\right| d x \leqq \frac{X}{2} \int_{0}^{x} y^{\prime 2} d x+\frac{h-X}{2} \int_{X}^{h} y^{\prime 2} d x
$$

which yields (1) on taking $X=h / 2$. Note that (1) is valid even if $y(x)$ has a discontinuity at $X=h / 2$, provided $y$ is absolutely continuous on both of the subintervals $[0, h / 2]$ and $[h / 2, h]$, with $y(0)=y(h)=0$.

To extend (1) to more general inequalities of this type, let $p, r$ denote functions which are continuous and positive in an interval $a<x<b$, and for which $(p r)^{\prime}$ is also continuous on this interval. Here, we may have $a=-\infty$, or $b=\infty$, or both. If $a<a^{\prime}<X<b$, and $y(x)$ is absolutely continuous on $a \leqq x \leqq X$ with

$$
y(x)=\int_{a}^{x} y^{\prime}(t) d t, \quad a \leqq x \leqq X
$$

we have

$$
0 \leqq \int_{a^{\prime}}^{x} p\left\{\left|y^{\prime}\right|-r|y|\right\}^{2} d x=\int_{a^{\prime}}^{x} p y^{\prime 2} d x+\int_{a^{\prime}}^{x} p r^{2} y^{2} d x-2 \int_{a^{\prime}}^{x} p r\left|y y^{\prime}\right| d x .
$$


Now,

$$
2 \int_{a^{\prime}}^{x} \operatorname{pr}\left|y y^{\prime}\right| d x=\left.2 p r \int_{a}^{x}\left|y y^{\prime}\right| d t\right|_{a^{\prime}} ^{x}-2 \int_{a^{\prime}}^{x}(p r)^{\prime}\left(\int_{a}^{x}\left|y y^{\prime}\right| d t\right) d x
$$

whence we obtain

$$
\begin{aligned}
2 p(X) r(X) \int_{a}^{x}\left|y y^{\prime}\right| d x \leqq & \int_{a^{\prime}}^{x} p y^{\prime 2} d x+\int_{a^{\prime}}^{x}\left\{p r^{2} y^{2}+2(p r)^{\prime} \int_{a}^{x}\left|y y^{\prime}\right| d t\right\} d x \\
& +2 p\left(a^{\prime}\right) r\left(a^{\prime}\right) \int_{a}^{a^{\prime}}\left|y y^{\prime}\right| d t
\end{aligned}
$$

We now choose $r(x)$ so that $p(x) r^{2}(x) \equiv-[p(x) r(x)]^{\prime}$ and, as in the proof of (1), obtain

(6) $\quad 2 p(X) r(X) \int_{a}^{x}\left|y y^{\prime}\right| d x \leqq \int_{a^{\prime}}^{x} p y^{\prime 2} d x+2 p\left(a^{\prime}\right) r\left(a^{\prime}\right) \int_{a}^{a^{\prime}}\left|y y^{\prime}\right| d x$.

We may choose

$$
r(x)=\frac{1}{p(x) \int_{a}^{x} \frac{d s}{p(s)}}>0, \quad a<x<X,
$$

assuming the existence of the integral involved. With this choice of $r(x)$, equality holds in (6) only if

$$
y(x) \equiv A \int_{a}^{x} \frac{d s}{p(s)} .
$$

We now assume that $y(x)$ satisfies

$$
\int_{a}^{x} p y^{\prime 2} d x<\infty, \quad y^{2}(x)=O\left(\int_{a}^{x} \frac{d s}{p}\right) \text { as } x \rightarrow a+.
$$

Then

$$
\begin{aligned}
p\left(a^{\prime}\right) r\left(a^{\prime}\right) \int_{a}^{a^{\prime}}\left|y y^{\prime}\right| d x \leqq \frac{1}{\int_{a}^{a^{\prime}} \frac{d x}{p}}\left(\int_{a}^{a^{\prime}} p y^{\prime 2} d x\right)^{1 / 2}\left(\int_{a}^{a^{\prime}} \frac{y^{2}}{p} d x\right)^{1 / 2} \\
=o(1) \frac{\left(\int_{a}^{a^{\prime}} \frac{y^{2}}{p} d x\right)^{1 / 2}}{\int_{a}^{a^{\prime}} \frac{d x}{p}} \leqq o(1) \frac{\left\{k \int_{a}^{a^{\prime}} \frac{1}{p}\left(\int_{a}^{x} \frac{d s}{p}\right) d x\right\}^{1 / 2}}{\int_{a}^{a^{\prime}} \frac{d x}{p}}=o(1)
\end{aligned}
$$


as $x \rightarrow a+$. We note that the second of the hypotheses (7) will be assured (with $o$ in place of $O$ ) if

$$
0<K_{1}(x-a)<p(x) \int_{a}^{x} \frac{d s}{p}<K_{2}(x-a) \text { near } x=a .
$$

(cf. Lemma 2.1 of [1]). Letting $a^{\prime} \rightarrow a$ in (6) we obtain the inequality

$$
\int_{a}^{x}\left|y y^{\prime}\right| d x \leqq \frac{1}{2} \int_{a}^{x} \frac{d x}{p} \int_{a}^{x} p y^{\prime 2} d x .
$$

We summarize our results as

THEOREM 1. Let $p(x)$ be positive and continuous on an interval $-\infty \leqq a<x$ $<X<\infty$, with $\int_{a}^{X} p^{-1} d x<\infty$. Let $y(x)$ be absolutely continuous on $a \leqq x \leqq X$, with

$$
\begin{gathered}
y(x)=\int_{a}^{x} y^{\prime}(t) d t, \quad a \leqq x \leqq X, \\
y^{2}(x)=O\left(\int_{a}^{x} \frac{d s}{p}\right)
\end{gathered}
$$

Then $y(x)$ satisfies the inequality (8). Moreover, equality holds in (8) only if

$$
y(x) \equiv A \int_{a}^{x} \frac{d s}{p}
$$

(this function being admissible).

Proceeding in the same way over the interval $X<x<b^{\prime}<b \leqq \infty$, and letting $b^{\prime} \rightarrow b$, we also obtain

Theorem 2. Let $p(x)$ be positive and continuous on an interval $X<x<b$ $\leqq \infty$, with $\int_{X}^{b} p^{-1} d x<\infty$. Let $y(x)$ be absolutely continuous on $X \leqq x \leqq b$, with

$$
\begin{aligned}
& y(x)=-\int_{x}^{b} y^{\prime}(t) d t, \quad X \leqq x \leqq b, \\
& y^{2}(x)=O\left(\int_{x}^{b} \frac{d s}{p}\right) \quad \text { as } x \rightarrow b-.
\end{aligned}
$$

Then $y(x)$ satisfies the inequality

$$
\int_{X}^{b}\left|y y^{\prime}\right| d x \leqq \frac{1}{2} \int_{x}^{b} \frac{d x}{p} \int_{x}^{b} p y^{\prime 2} d x
$$

where equality holds only if 


$$
y(x) \equiv B \int_{x}^{b} \frac{d s}{p} .
$$

To obtain the extension of (1), we combine the inequalities (8) and (9), and take $X$ to be the unique point for which

$$
\int_{a}^{x} \frac{d x}{p}=\int_{x}^{b} \frac{d x}{p}=K .
$$

This yields

Theorem 3. Let $p(x)$ be positive and continuous on an interval $a<x<b$, with $\int_{a}^{b} p^{-1} d x<\infty$. Let $y(x)$ be absolutely continuous on each of the subintervals $a \leqq x \leqq X, X \leqq x \leqq b$, with

$$
\begin{array}{rlrl}
y(x) & =\int_{a}^{x} y^{\prime}(t) d t, a \leqq x \leqq X, & y(x) & =-\int_{x}^{b} y^{\prime}(t) d t, X \leqq x \leqq b, \\
y^{2}(x) & =O\left(\int_{a}^{x} \frac{d s}{p}\right) \text { as } x \rightarrow a+, \quad y^{2}(x)=O\left(\int_{x}^{b} \frac{d s}{p}\right) \text { as } x \rightarrow b-.
\end{array}
$$

Then

$$
\int_{a}^{b}\left|y y^{\prime}\right| d x \leqq \frac{K}{2} \int_{a}^{b} p y^{\prime 2} d x .
$$

Here, $K($ and $X)$ are defined by (10). Equality holds in (11) only if

$$
y(x) \equiv \begin{cases}A \int_{a}^{x} \frac{d s}{p(s)}, & a \leqq x<X, \\ B \int_{x}^{b} \frac{d s}{p(s)}, & X<x \leqq b .\end{cases}
$$

Opial's inequality (1) is the special case obtained by taking $a=0, p(x) \equiv 1$ in Theorem 3. As further examples of Theorem 3 we have the inequalities

$$
\begin{aligned}
& \int_{-1}^{1}\left|y y^{\prime}\right| d x \leqq \frac{1}{3} \int_{-1}^{1} \frac{y^{\prime 2}}{1-x^{2}} d x \\
& \int_{-1}^{1}\left|y y^{\prime}\right| d x \leqq \frac{\pi}{4} \int_{-1}^{1} \frac{y^{\prime 2}}{\left(1-x^{2}\right)^{1 / 2}} d x
\end{aligned}
$$

where in both cases, it suffices to have

$$
y^{2}(x)=O(x+1) \text { as } x \rightarrow-1, \quad y^{2}(x)=O(1-x) \text { as } x \rightarrow 1 .
$$

Examples of the preceding theorems on infinite intervals are 


$$
\int_{0}^{\infty}\left|y y^{\prime}\right| d x \leqq \frac{1}{4} \int_{0}^{\infty} e^{x} y^{\prime 2} d x
$$

when $y^{2}(x)=O(x)$ as $x \rightarrow 0, y^{2}(x)=O\left(e^{-x}\right)$ as $x \rightarrow \infty$;

$$
\int_{-\infty}^{\infty}\left|y y^{\prime}\right| d x \leqq \frac{\pi}{4} \int_{-\infty}^{\infty}\left(1+x^{2}\right) y^{\prime 2} d x,
$$

when $y^{2}(x)=O\left(|x|^{-1}\right)$ as $|x| \rightarrow \infty$. If we remove the restriction $y^{2}(x)=O(x)$ in (14), we must replace the constant $1 / 4$ by $1 / 2$.

Finally, we note that modifications of the proof lead to further inequalities similar to (8), (9) or (11).

For example, in the proof of Theorem 1, if we replace $p$ by $p q$, and choose $r$ as before, we obtain the inequality

$$
\int_{a}^{x} q\left|y y^{\prime}\right| d x \leqq \frac{1}{2} \int_{a}^{x} \frac{d x}{p} \int_{a}^{x} p q y^{\prime 2} d x .
$$

Here, $p, q$ are positive and continuous with $q$ nonincreasing on $a<x<X$; $y(x)$ is any function, absolutely continuous on $a \leqq x \leqq X$, with $y(a)=0$ and

$$
y^{2}(x)=O\left(q^{-1}(x) \int_{a}^{x} \frac{d s}{p}\right) \text { as } x \rightarrow a+.
$$

Equality can never hold in (16) unless $q \equiv$ constant, or $y \equiv 0$.

\section{REFERENCES}

1. P. R. Beesack, Hardy's inequality and its extensions, Pacific J. Math. 11 (1961), 39-61.

2. C. Olech, $A$ simple proof of a certain result of $Z$. Opial, Ann. Polon. Math. 8 (1960), 61-63.

3. Z. Opial, Sur une inégalité, Ann. Polon. Math. 8 (1960), 29-32.

Carleton University,

OtTawa, Canada 